\title{
Synthesis of P(NIPAM-co-Am)/Mesoporous Silica Composites and Their Temperature- Responsive Anion Exchange
}

\author{
Kenji Murakami*, Yasuto Sato, Yukihiko Inoue \\ Department of Materials Science, Faculty of Engineering Science, Akita University, Akita City, Japan \\ Email: ${ }^{*}$ murakami@gipc.akita-u.ac.jp
}

Received 24 April 2015; accepted 13 June 2015; published 16 June 2015

Copyright (C) 2015 by authors and Scientific Research Publishing Inc.

This work is licensed under the Creative Commons Attribution International License (CC BY). http://creativecommons.org/licenses/by/4.0/

(c) (i) Open Access

\begin{abstract}
The purpose of this study is to examine the structure and the temperature-responsive anion exchange property of amino-functionalized mesoporous silica coated with temperature-responsive copolymer, poly $(N$-isopropylacrylamide-co-acrylamide) (P(NIPAM-co-Am)). For this purpose, the composites which contained 0,10 , or $20 \mathrm{wt} \%$ of Am were synthesized. From the TG results, it was found that the amounts of copolymer immobilized on the mesoporous silica were $1.6-2.6 \mathrm{wt} \%$. XRD patterns revealed that the structures of composites were hexagonal and almost the same as that of original mesoporous silica without polymer. At low temperature the methyl orange (MO) anions adsorbed and desorbed reversibly with changing $\mathrm{pH}$ of the solution, while at high temperature the MO anions did not. This temperature, at which the amount of adsorbed MO anions changed considerably, shifted to the higher temperature side with increasing the amount of added Am.
\end{abstract}

\section{Keywords}

Mesoporous Silica, Temperature-Responsive Anion Exchanger, $N$-Isopropylacrylamide, Acrylamide, Transition Temperature

\section{Introduction}

Materials composed of stimuli-responsive polymer and mesoporous silica have been synthesized widely [1]-[11]. Such composites are expected to be used as a carrier for drug delivery system (DDS), a column packing agent for stimuli-responsive chromatography, and so on. We also synthesized the amino-functionalized mesoporous

\footnotetext{
${ }^{*}$ Corresponding author.
}

How to cite this paper: Murakami, K., Sato, Y. and Inoue, Y. (2015) Synthesis of P(NIPAM-co-Am)/Mesoporous Silica Composites and Their Temperature-Responsive Anion Exchange. Journal of Materials Science and Chemical Engineering, 3, 7-15. http://dx.doi.org/10.4236/msce.2015.37002 
silica coated with poly ( $N$-isopropylacrylamide) (PNIPAM) and studied their temperature dependence of the amount of anion exchange [12]-[15]. The mesoporous silica is effective for the adsorption of large molecules such as amino acids, proteins, and sugars, because it has large uniform pores (about $3 \mathrm{~nm}$ ) and large specific surface area (about $700 \mathrm{~m}^{2} / \mathrm{g}$ ). On the other hand, PNIPAM, which is one of the thermosensitive polymers, is well-known to swell due to the hydration of polymer below its lower critical solution temperature (LCST, about $32^{\circ} \mathrm{C}$ ) and shrink due to the dehydration above the LCST. In our previous studies [12] [13], we showed that the synthesized composites had the following characteristics. Below the LCST of the polymer, the methyl orange (MO) anions could be adsorbed and desorbed reversibly depending on the $\mathrm{pH}$ of the aqueous solution. Above the LCST, on the other hand, the MO anions could not be adsorbed and desorbed independent of the $\mathrm{pH}$ of the aqueous solution. These phenomena were considered to be due to the change in the surface property of the synthesized composite with the change in the solution temperature. That is, the MO anions could easily penetrate through the PNIPAM layer because of the hydrophilic property of the PNIPAM on the external surface of the composite below the LCST, while the MO anions could hardly penetrate through the PNIPAM layer because of the hydrophobic property of the PNIPAM above the LCST.

In this way, the PNIPAM on the external surface of mesoporous silica is considered to play a role of gate for the pore. Next purpose of this study is to control the temperature at which the anion exchange property of the composite changed suddenly. Hereafter, this temperature is referred to as a transition temperature. Previously, we reported that the transition temperature shifted to the higher temperature side by the addition of a crosslinking agent, $N, N^{\prime}$-methylenebisacrylamide (BIS), to the NIPAM monomer solution and then the synthesis of BIScrosslinked PNIPAM [14]. However, the transition temperature increased only by $5^{\circ} \mathrm{C}$, though $10 \mathrm{wt} \%$ of BIS was added. In order to shift the transition temperature of the composite to the much higher temperature, the copolymer of NIPAM and acrylamide (Am) was immobilized on the mesoporous silica in this study. Wu et al. described that the LCST increased in the copolymerization of PNIPAM and a monomer with high hydrophilicity such as acrylamide, while the LCST decreased in the copolymerization of PNIPAM and a monomer with high hydrophobicity such as butyl methacrylate [16]. However, the transition temperature of the mesoporous silica covered with the P(NIPAM-co-Am) copolymer has not been clarified yet. In this study, the influence of the addition of the Am on the structure and the transition temperature of the prepared composites was examined.

\section{Experimental}

\subsection{Synthesis of P(NIPAM-co-Am)/Amino-Functionalized Mesoporous Silica Composite}

Figure 1 shows the procedure for the synthesis of P(NIPAM-co-Am)/mesoporous silica composites.

The amino-functionalized silica/surfactant mesophase was prepared according to the method reported by Grun et al. [17]. A surfactant, hexadecyl trimethyl ammonium bromide $(2.4 \mathrm{~g})\left(\left[\mathrm{CH}_{3}\left(\mathrm{CH}_{2}\right)_{15} \mathrm{~N}_{\left(\mathrm{CH}_{3}\right)}\right)_{3} \mathrm{Br}, \mathrm{CTMABr}, \mathrm{Na}-\right.$ calai tesque) was dissolved in a mixture of $120 \mathrm{ml}$ of distilled water and $9.5 \mathrm{ml}$ of $28 \mathrm{wt} \%$ ammonia solution at $80^{\circ} \mathrm{C}$. After the solution containing surfactant was cooled to room temperature, a mixture of $9.9 \mathrm{ml}$ of tetraethylorthosilicate (TEOS, Nacalai tesque), as a source of silica, and $0.5 \mathrm{ml}$ of 3-aminopropyl triethoxysilane (APTES, Nacalai tesque), providing a functional group having anion-exchange ability, was slowly added to the solution containing surfactant under stirring at room temperature for $1 \mathrm{~h}$. Then, the resulting precipitate was filtered, washed with distilled water, and dried at $60^{\circ} \mathrm{C}$ for $24 \mathrm{~h}$. In this way, an amino-functionalized silica/surfactant mesophase was prepared.

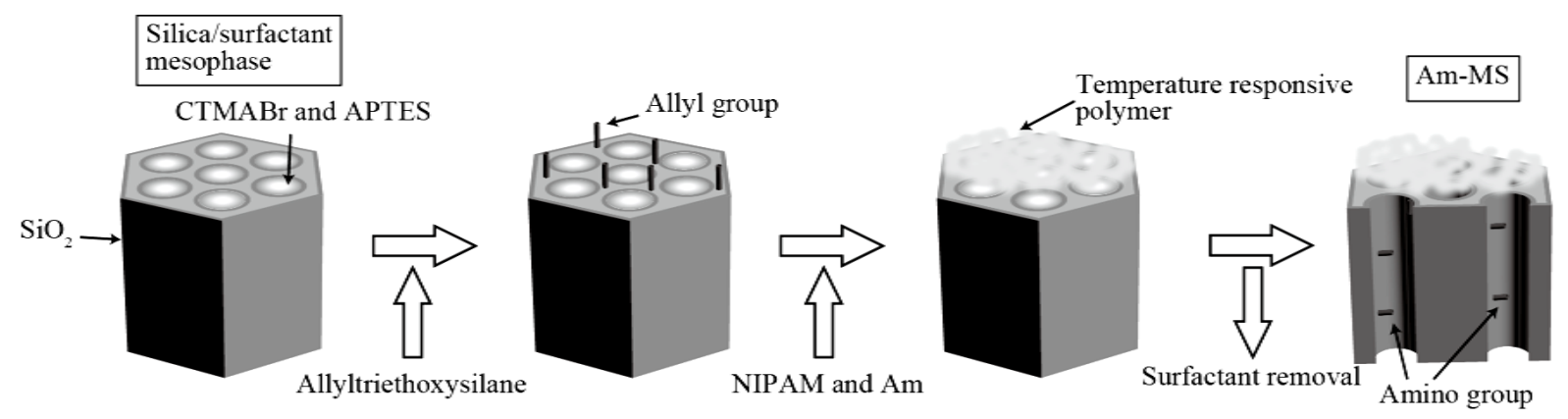

Figure 1. Schematic illustration of synthesis of mesoporous silica coated with P(NIPAM-co-Am) copolymer. 
The second step is to immobilize allyl groups on the external surface of the mesophase for anchoring of the copolymer. After $4 \mathrm{~g}$ of the amino-functionalized silica/surfactant mesophase was added into a mixture of 120 $\mathrm{ml}$ of toluene (Nacalai tesque) and $1 \mathrm{ml}$ of allyltriethoxysilane (Shin-Etsu Chemical), the suspension was refluxed at $200^{\circ} \mathrm{C}$ for $4 \mathrm{~h}$. Then, the suspension was filtered, washed with ethanol, and dried at $60^{\circ} \mathrm{C}$ for $24 \mathrm{~h}$.

The third step is to copolymerize the NIPAM and Am in the presence of amino-functionalized silica/surfacetant mesophase with allyl groups $(1 \mathrm{~g})$. A mixture of NIPAM and Am monomers (total weight is $0.5 \mathrm{~g}$ ) was dissolved in $30 \mathrm{ml}$ of distilled water. The mixed ratio of Am was set to 0, 10, and $20 \mathrm{wt} \%$. The polymerization was carried out at $30^{\circ} \mathrm{C}$ for $4.5 \mathrm{~h}$ with stirring under a nitrogen atmosphere, after $3 \mathrm{ml}$ of ammonium persulfate (APS) aqueous solution (concentration: $20 \mathrm{mg} / \mathrm{ml}$ ), as a radical polymerization initiator, was added into the suspension by using micro syringe. The resultant product was filtered, washed with distilled water, and dried at $60^{\circ} \mathrm{C}$ for 24 h.

Finally, the surfactant was removed from the mesophase by acidic solvent extraction. The sample was added to a mixed solution of $3.5 \mathrm{ml}$ of concentrated hydrochloric acid (35\% conc.) and $150 \mathrm{ml}$ of ethanol. The suspension was heated at reflux $\left(200^{\circ} \mathrm{C}\right)$ for $2 \mathrm{~h}$, and then the resulting precipitate was filtered, washed with ethanol, and dried at $60^{\circ} \mathrm{C}$ for $24 \mathrm{~h}$. Hereafter, the samples with $0,10,20 \mathrm{wt} \%$ of Am were designated as Am0-MS, Am10-MS, and Am20-MS, respectively. As a reference sample, the mesoporous silica without temperatureresponsive polymer was also prepared and referred to as MS.

\subsection{Characterization of Composites}

X-ray diffraction patterns were collected using a Rigaku Ultima IV diffractometer with CuK $\alpha$ radiation source with a scan speed $2.000^{\circ} / \mathrm{min}$ from $2 \theta=1.500^{\circ}$ to $10.000^{\circ}$. The divergence slit was $1.0^{\circ}$, the receiving slit was $0.30 \mathrm{~mm}$, and the sampling width was $0.020^{\circ}$. Nitrogen adsorption measurements were performed at $77 \mathrm{~K}$ on a BEL Japan BELSORP mini II. The specific surface area was calculated by BET analysis in the relative pressure ranging from 0.1 to 0.3 . The pore size distribution was calculated by BJH method. Before the measurement, the samples were pre-treated at $150^{\circ} \mathrm{C}$ for $4 \mathrm{~h}$ under vacuum. TG measurements were carried out using a Shimadzu TGA-50 in $40 \mathrm{ml} / \mathrm{min}$ of air flow at a heating rate of $10^{\circ} \mathrm{C} / \mathrm{min}$ up to $1000^{\circ} \mathrm{C}$.

\subsection{Ion Exchange of Methyl Orange Anions}

The synthesized composites were used in the ion-exchange experiments. After $0.1 \mathrm{~g}$ of sample was added to 100 ppm of methyl orange (MO) aqueous solution (100 ml), the suspension was stirred magnetically at a speed of $1000 \mathrm{rpm}$. At first, the temperature of the aqueous solution was set to $25^{\circ} \mathrm{C}$. The $\mathrm{pH}$ of the solution was adjusted 8.6 - 9.0 by the addition of $\mathrm{NH}_{3}$ aqueous solution (28 wt\%) to desorb $\mathrm{MO}$ anions from the composite. Then, the temperature of the aqueous solution increased to the desired temperature between $25^{\circ} \mathrm{C}$ and $55^{\circ} \mathrm{C}$, and the $\mathrm{pH}$ of the solution was adjusted to $2.8-3.3$ by the addition of $4 \mathrm{M}$ of hydrochloric acid. Sampling was repeated in every $30 \mathrm{~min}$ and the concentration of MO anions in the supernatant liquid was analyzed with a UV-Vis spectrometer (JASCO V-630) at $510 \mathrm{~nm}$. The amount of MO anions adsorbed on adsorbent was calculated by the mass balance before and after adsorption.

\section{Results and Discussion}

\subsection{Characterization of Products}

The XRD patterns for MS, Am0-MS, Am10-MS, and Am20-MS are shown in Figure 2. In the MS sample, the appearance of three diffraction peaks that can be attributed to a hexagonal lattice is typical of MCM-41 type mesoporous silica. The peak intensity decreased slightly and the d spacing of (100) reflection, $\mathrm{d}_{100}$, increased from 41.7 to $42.9 \AA$ with the amount of Am addition. Figure 3 shows the nitrogen adsorption-desorption isotherms for MS, Am0-MS, Am10-MS, and Am20-MS. All the samples were found to have mesopores because these isotherms exhibited the characteristic type-IV adsorption-desorption patterns. The BET specific surface areas for MS, Am0-MS, Am10-MS, and Am20-MS were 810, 890, 870, and $840 \mathrm{~m}^{2} / \mathrm{g}$, respectively, which indicates that the copolymer did not exist in the mesopore. As shown in Figure 4, the average pore diameters determined by BJH analysis were $2.7 \mathrm{~nm}$ independent of the presence of polymer. In this way, little change in the structural properties such as the silica framework, the specific surface area and the pore size distribution was observed, indicating that the immobilization of copolymer hardly affected the structure of mesoporous silica. 


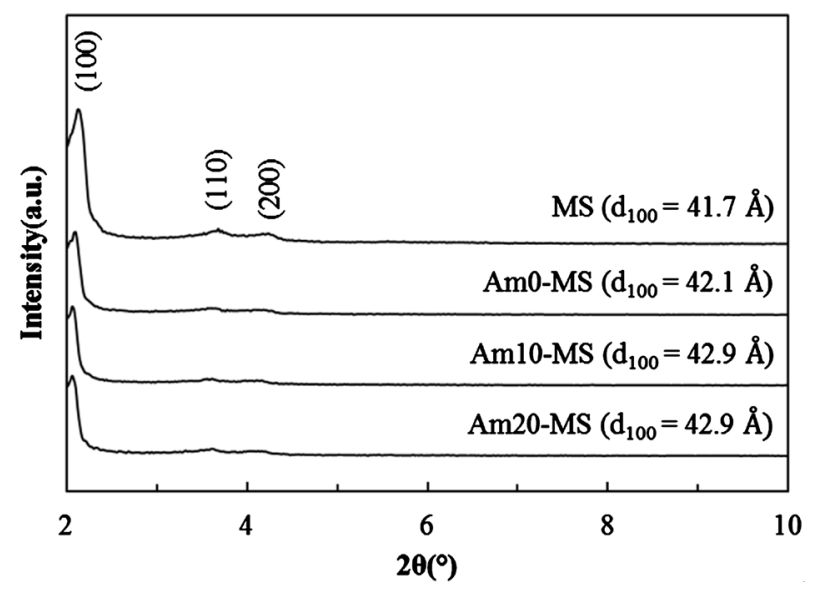

Figure 2. XRD patterns of MS, Am0-MS, Am10-MS, and Am20-MS samples.

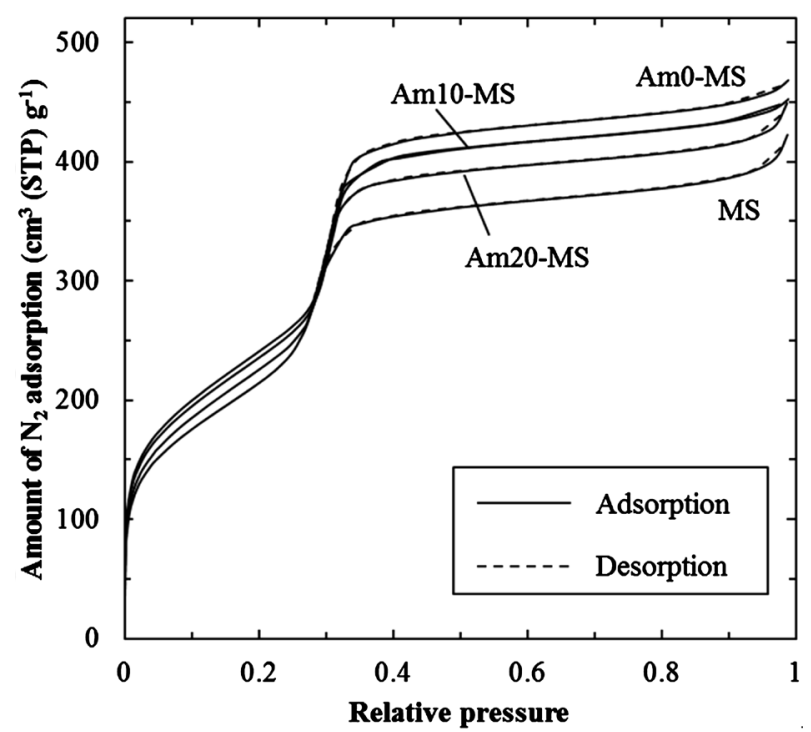

Figure 3. Nitrogen adsorption-desorption isotherms of MS, Am0-MS, Am10-MS, and Am20-MS samples.

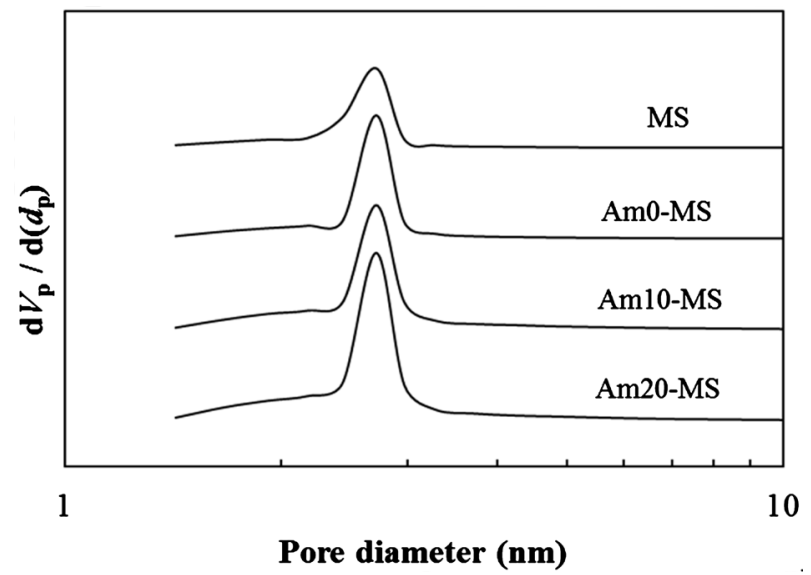

Figure 4. Pore size distributions of MS, Am0-MS, Am10-MS, and Am20-MS samples. 
The thermogravimetric curves for MS, Am0-MS, Am10-MS, and Am20-MS were shown in Figure 5. In order to remove the adsorbed water from the composites, the samples were dried at $100^{\circ} \mathrm{C}$ prior to the TG measurement. In the case of MS, the decrease in the weight was $12.2 \mathrm{wt} \%$ up to $1000^{\circ} \mathrm{C}$, which corresponds to the decomposition of aminopropyl groups inside the pore, the allyl groups on the external surface of the mesoporous silica, and the hydroxyl groups present on the surface of mesoporous silica [18]. Thus, the amount of PNIPAM or P(NIPAM-co-Am) immobilized on the mesoporous silica can be estimated from the difference in weight between MS and composites at $1000^{\circ} \mathrm{C}$. As the result, the amount of immobilized PNIPAM or P(NIPAM-co-Am) was 1.6 - $2.6 \mathrm{wt} \%$, which was rather a low value. This is because two radical reaction occurred simultaneously: one was the polymerization of the NIPAM or Am monomer, and the other was the immobilization of PNIPAM or P(NIPAM-co-Am) on the external surface of the mesoporous silica.

In the previous study [19], the amino groups present in the MS prepared by the same method as this study was estimated to be $0.87 \mathrm{wt} \%$ from the elemental analysis. Thus, the amount of the amino groups was calculated at $0.62 \mathrm{mmol} / \mathrm{g}-\mathrm{SiO}_{2}$. Because the specific surface area for MS sample was $810 \mathrm{~m}^{2} / \mathrm{g}$, the occupied surface area per one amino group was about $220 \AA^{2} /$ amino group $\left(=\left(810 \mathrm{~m}^{2} / \mathrm{g}\right) /(0.62 \mathrm{mmol} / \mathrm{g})\right)$, indicating that the amino group was distributed sparsely.

\subsection{Temperature Dependence on the Amount of Adsorbed Methyl Orange (M0) Anions}

The results of adsorption-desorption experiments of MO anions for MS, Am0-MS, Am10-MS, and Am20-MS are shown in Figure 6. The result of MS in Figure 6(a) was almost the same that in the previous study [12]: the $\mathrm{MO}$ anions adsorbed and desorbed reversibly and repeatedly with changing the $\mathrm{pH}$ of the solution at 25 and $35^{\circ} \mathrm{C}$. Describing the results in detail, the amount of the adsorbed $\mathrm{MO}$ anions was about $0.25 \mathrm{mmol} / \mathrm{g}$ in the low $\mathrm{pH}$ region, while the amount of the adsorbed MO anions was about $0.018 \mathrm{mmol} / \mathrm{g}$ in the high $\mathrm{pH}$ region. This adsorption-desorption behavior for MS sample is typical for the anion exchanger.

Unlike to the case of MS sample, the amount of adsorbed MO anions for Am0-MS shown in Figure 6(b) depended on the solution temperature. At $25^{\circ} \mathrm{C}$ and $30^{\circ} \mathrm{C}$, the amount of the adsorbed $\mathrm{MO}$ anions was about 0.26 $\mathrm{mmol} / \mathrm{g}$ in the low $\mathrm{pH}$ region, while the amount of the adsorbed $\mathrm{MO}$ anions was about $0.024 \mathrm{mmol} / \mathrm{g}$ in the high $\mathrm{pH}$ region, indicating that the adsorption-desorption behavior at low temperature was almost the same as the case of MS. On the other hand, the amount of the adsorbed MO anions was almost constant at $0.02-0.03 \mathrm{mmol} / \mathrm{g}$ independent of the $\mathrm{pH}$ of the aqueous solution. This suggests that the PNIPAM exist near the entrances of mesopores. In other words, the dehydrated and shrunken PNIPAM prevents the MO anions from entering into and leaving the mesopores above the LCST of the PNIPAM. Similar tendency was seen in the cases of Am10-MS and Am20-MS, as shown in Figure 6(c) and Figure 6(d), respectively. However, the transition temperature for Am10-MS and Am20-MS were different from that for Am0-MS.

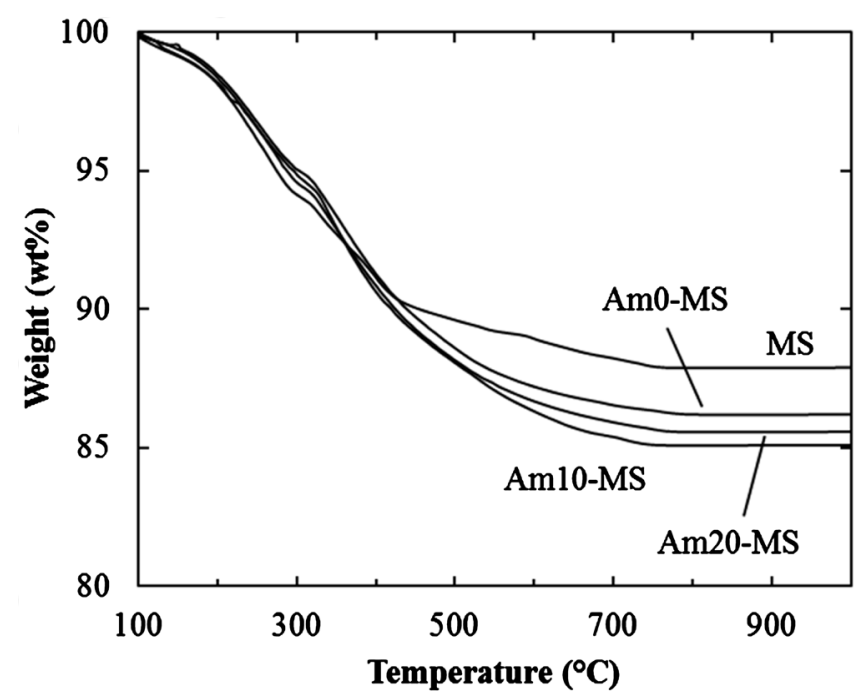

Figure 5. Thermogravimetric curves of MS, Am0-MS, Am10-MS, and Am20-MS samples. 

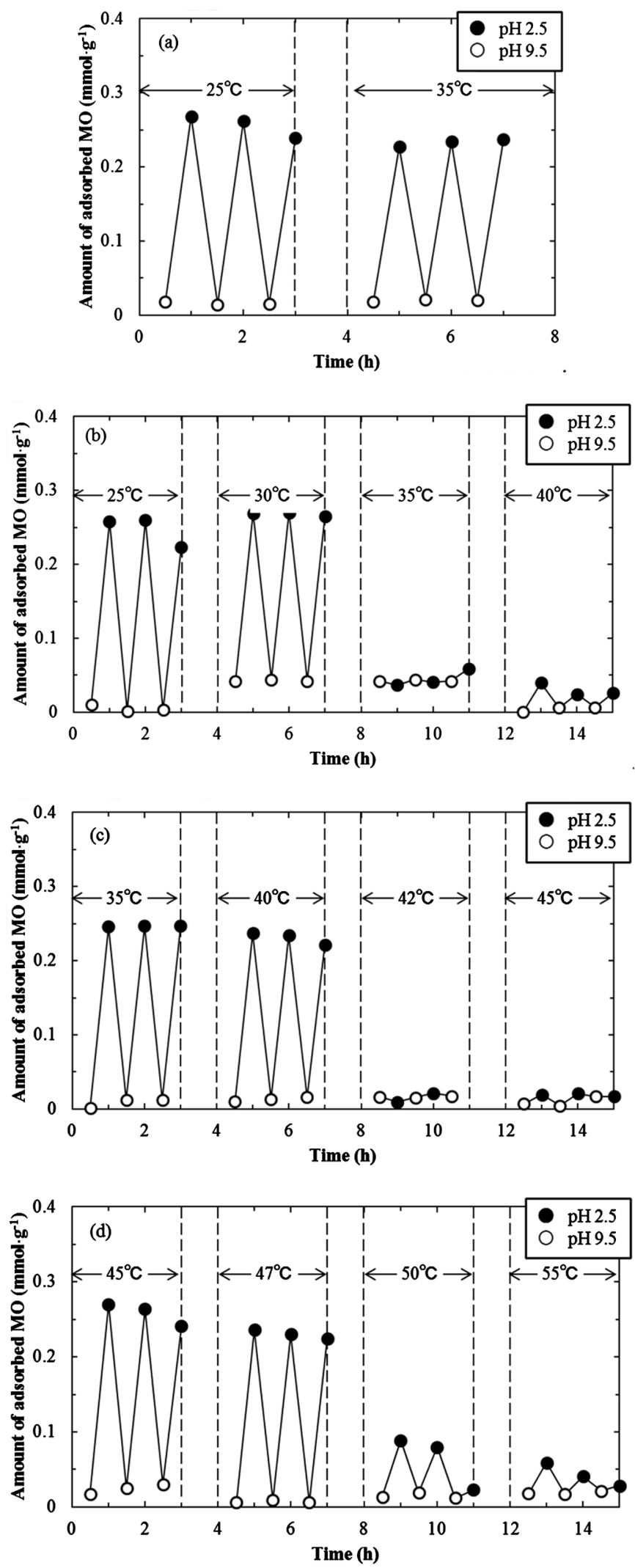

Figure 6. Change in the amount of adsorbed $\mathrm{MO}$ ions at various temperatures for (a) MS, (b) Am0-MS, (c) Am10-MS, and (d) Am20-MS samples. 
Figure 7 shows the average amount of adsorbed $\mathrm{MO}$ anions at low $\mathrm{pH}$ against the solution temperature. In this figure, the temperature at which the amount of adsorbed MO anions changed suddenly was the transition temperature. It was found that the transition temperatures for Am0-MS, Am10-MS, and Am20-MS were $30^{\circ} \mathrm{C}$ $35^{\circ} \mathrm{C}, 40^{\circ} \mathrm{C}-42^{\circ} \mathrm{C}$, and $47^{\circ} \mathrm{C}-50^{\circ} \mathrm{C}$, respectively. That is, the transition temperature shifted to the higher temperature side with increasing the amount of added Am. Table 1 shows the comparison of transition temperature between the bulk polymer [16] and the polymer immobilized on the mesoporous silica. The transition temperature for Am0-MS was almost the same as that for bulk PNIPAM, while the transition temperatures for Am10-MS and Am20-MS were higher than those for bulk copolymer by about $5^{\circ} \mathrm{C}$. This would be because the hydration and dehydration behavior is restricted by the immobilization of copolymer on the surface of mesoporous silica.

The relation between the amount of the added Am monomer (mol\%) and the transition temperature is shown in Figure 8. In this figure, the previous results which were obtained in the case of the addition of crosslinking agent, BIS, are also plotted. Both results were plotted on the same straight line and there was a tendency that the transition temperature increased linearly with increasing the amount of additives such as BIS and Am. It is very interesting to be able to control the transition temperature by only the amount of additives. However, in the case of BIS, it was difficult to add more than $10 \mathrm{wt} \%$ of BIS, because the three-dimensional network was formed. On the other hand, the amount of added Am can increase further, so that the transition temperature is expected to shift to the much higher temperature side.

\section{Conclusion}

In this study, the amino-functionalized mesoporous silicas coated with P(NIPAM-co-Am) were synthesized. Even if the amount of added Am increased up to $20 \mathrm{wt} \%$, the structure of composite maintained a hexagonal structure. There was no influence on the porous property of the mesoporous silica, because the amount of immobilized polymer was very small at $1.6-2.6 \mathrm{wt} \%$. The transition temperatures for Am0-MS, Am10-MS, and Am20-MS were $30^{\circ} \mathrm{C}-35^{\circ} \mathrm{C}, 40^{\circ} \mathrm{C}-42^{\circ} \mathrm{C}$, and $47^{\circ} \mathrm{C}-50^{\circ} \mathrm{C}$, respectively, and it was found that the transition temperature of the composite shifted to the higher temperature side with increasing the amount of added Am.

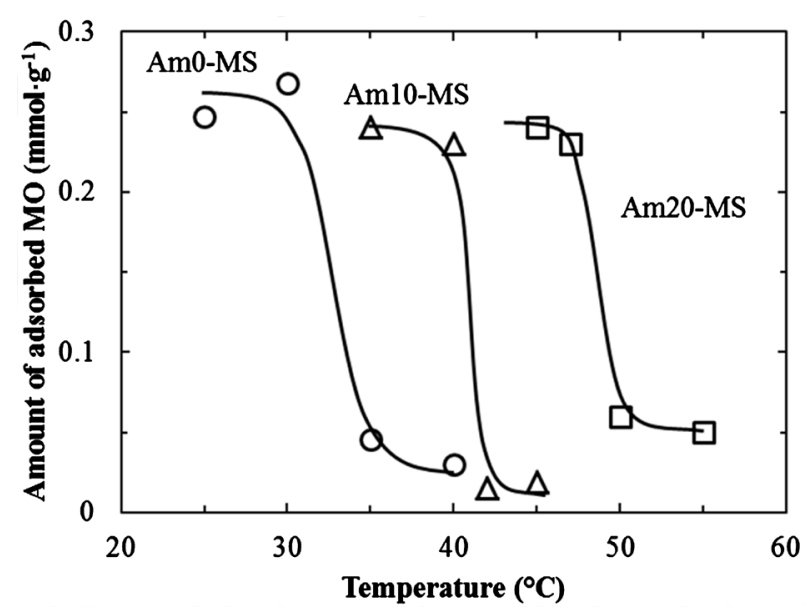

Figure 7. The solution temperature dependence of average amount of adsorbed $\mathrm{MO}$ ions in the low $\mathrm{pH}$ region for Am0-MS, Am10-MS, and Am20MS samples.

Table 1. Transition temperature for the composite (this study) and the bulk polymer [16].

\begin{tabular}{ccc}
\hline Sample & Composite & Bulk polymer \\
\hline Am0-MS & $30^{\circ} \mathrm{C}-35^{\circ} \mathrm{C}$ & $32.5^{\circ} \mathrm{C}$ \\
Am10-MS & $40^{\circ} \mathrm{C}-42^{\circ} \mathrm{C}$ & $38.7^{\circ} \mathrm{C}$ \\
Am20-MS & $47^{\circ} \mathrm{C}-50^{\circ} \mathrm{C}$ & $45.4^{\circ} \mathrm{C}$ \\
\hline
\end{tabular}




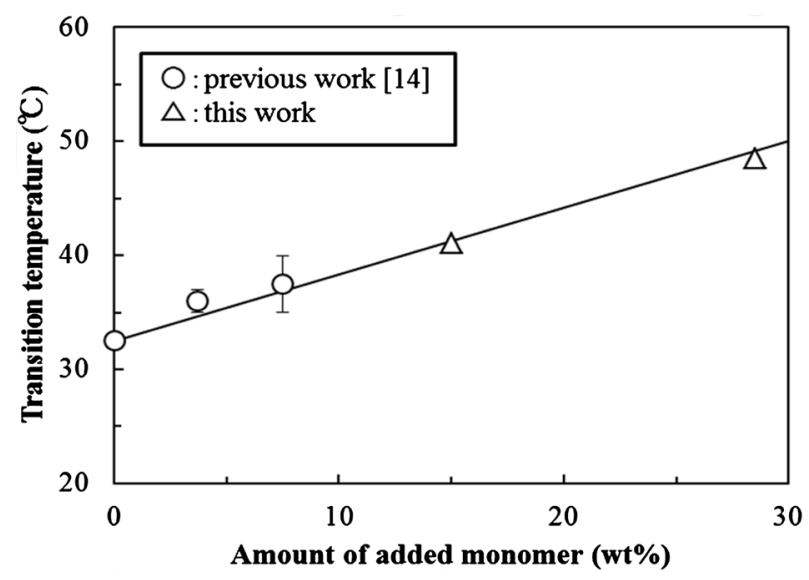

Figure 8. Relationship between the amount of added additives such as Am (this work) and BIS [14] and transition temperature.

\section{Acknowledgements}

This work was supported financially by a Grant-in-Aid for Scientific Research (C) (No. 24560916) from Japan Society for the Promotion of Science (JSPS).

\section{References}

[1] Xu, W., Gao, Q., Xu, Y., Wu, D. and Sun, Y. (2009) pH-Controlled Drug Release from Mesoporous Silica Tablets Coated with Hydroxypropyl Methylcellulose Phthalate. Materials Research Bulletin, 44, 606-612. http://dx.doi.org/10.1016/j.materresbull.2008.07.001

[2] Kim, H-J., Matsuda, H., Zhou, H. and Honma, I. (2006) Ultrasound-Triggered Smart Drug Release from a Poly(Dimethylsiloxane)-Mesoporous Silica Composite. Advanced Materials, 18, 3083-3088. http://dx.doi.org/10.1002/adma.200600387

[3] Mal, N.K., Fujiwara, M. and Tanaka, Y. (2003) Photocontrolled Reversible Release of Guest Molecules from Coumarin-Modified Mesoporous Silica. Nature, 421, 350-353. http://dx.doi.org/10.1038/nature01362

[4] Rama Rao, G.V., Krug, M.E., Balamurugan, S., Xu, H., Xu, Q. and Lopez, G.P. (2002) Synthesis and Characterization of Silica-Poly( $N$-Isopropylacrylamide) Hybrid Membranes: Switchable Molecular Filters. Chemistry of Materials, 14, 5075-5080. http://dx.doi.org/10.1021/cm020627b

[5] Fu, Q., Rama Rao, G.V., Ista, L.K., Wu, Y., Andrzejewski, B.P., Sklar, L.A., Ward, T.L. and Lopez, G.P. (2003) Control of Molecular Transport through Stimuli-Responsive Ordered Mesoporous Materials. Advanced Materials, 15, 1262-1266. http://dx.doi.org/10.1002/adma.200305165

[6] Fu, Q., Rama Rao, G.V., Ward, T.L., Lu, Y. and Lopez, G.P. (2007) Thermoresponsive Transport through Ordered Mesoporous Silica/PNIPAAm Copolymer Membranes and Microspheres. Langmuir, 23, 170-174. http://dx.doi.org/10.1021/la062770f

[7] Tian, B.-S. and Yang, C. (2009) Temperature-Responsive Nanocomposites Based on Mesoporous SBA-15 Silica and PNIPAAm: Synthesis and Characterization. Journal of Physical Chemistry C, 113, 4925-4931. http://dx.doi.org/10.1021/jp808534q

[8] Wen, H., Guo, J., Chang, B. and Yang, W. (2013) pH-Responsive Composite Microspheres Based on Magnetic Mesoporous Silica Nanoparticle for Drug Delivery. European Journal of Pharmaceutics and Biopharmaceutics, 84, 91-98. http://dx.doi.org/10.1016/j.ejpb.2012.11.019

[9] Yu, F., Tang, X. and Pei, M. (2013) Facile Synthesis of PDMAEMA-Coated Hollow Mesoporous Silica Nanoparticles and Their pH-Responsive Controlled Release. Microporous and Mesoporous Materials, 173, 64-69. http://dx.doi.org/10.1016/j.micromeso.2013.02.012

[10] Zhao, Q., Wang, C., Liu, Y., Wang, J., Gao, Y., Zhang, X., Jiang, T. and Wang, S. (2014) PEGylated Mesoporous Silica as a Redox-Responsive Drug Delivery System for Loading Thiol-Containing Drugs. International Journal of Pharmaceutics, 477, 613-622. http://dx.doi.org/10.1016/j.ijpharm.2014.10.056

[11] Wang, Y., Han, N., Zhao, Q., Bai, L., Li, J., Jiang, T. and Wang, S. (2015) Redox-Responsive Mesoporous Silica as Carriers for Controlled Drug Delivery: A Comparative Study Based on Silica and PEG Gatekeepers. European Journal 
of Pharmaceutical Sciences, 72, 12-20. http://dx.doi.org/10.1016/j.ejps.2015.02.008

[12] Murakami, K., Yu, X., Watanabe, S., Kato, T., Inoue, Y. and Sugawara, K. (2011) Synthesis of Thermosensitive Polymer/Mesoporous Silica Composite and Its Temperature Dependence of Anion Exchange Property. Journal of Colloid and Interface Science, 354, 771-776. http://dx.doi.org/10.1016/j.jcis.2010.10.040

[13] Murakami, K., Yu, X., Kato, T., Inoue, Y. and Sugawara, K. (2012) Synthesis of Temperature-Responsive Anion Exchanger via Click Reaction. Journal of Colloid and Interface Science, 376, 189-195. http://dx.doi.org/10.1016/j.jcis.2012.02.040

[14] Murakami, K., Watanabe, S., Kato, T. and Sugawara, K. (2013) Transition Temperature Control of Adsorption-Desorption Property of PNIPAM/Mesoporous Silica Composite by Addition of Crosslinking Agent. Colloid and Surfaces A, 419, 223-227. http://dx.doi.org/10.1016/j.colsurfa.2012.11.074

[15] Murakami, K., Kato, T. and Sugawara, K. (2013) Influence of Amount of Thermosensitive Polymer on Anion-Exchange Properties of Thermosensitive Polymer/Mesoporous Silica Composite. Kagakukogaku Ronbunshu, 39, $206-212$. http://dx.doi.org/10.1252/kakoronbunshu.39.206

[16] Wu, D., Liu, X., Yu, S., Liu, M. and Gao, C. (2010) Modification of Aromatic Polyamide Thin-Film Composite Reverse Osmosis Membranes by Surface Coating of Thermo-Responsive Copolymers P(NIPAM-co-Am). I: Preparation and Characterization. Journal of Membrane Science, 352, 76-85. http://dx.doi.org/10.1016/j.memsci.2010.01.061

[17] Grun, M., Unger, K.K., Matsumoto, A. and Tsutsumi, K. (1999) Novel Pathways for the Preparation of Mesoporous MCM-41 Materials: Control of Porosity and Morphology. Microporous and Mesoporous Materials, 27, 207-216. http://dx.doi.org/10.1016/S1387-1811(98)00255-8

[18] Jaroniec, M., Kruk, M., Shin, H.J., Ryoo, R., Sakamoto, Y. and Terasaki, O. (2001) Comprehensive Characterization of Highly Ordered MCM-41 Silicas Using Nitrogen Adsorption, Thermogravimetry, X-Ray Diffraction and Transmission Electron Microscopy. Microporous and Mesoporous Materials, 48, 127-134. http://dx.doi.org/10.1016/S1387-1811(01)00335-3

[19] Murakami, K., Fuda, K. and Sugai, M. (2007) Geometrical Study on Change of Pore Volume of MCM-41 Functionalized with Aminopropyl Groups. Materials Research Society Symposium Proceedings, 1056. 